\title{
Educação ambiental: possíveis caminhos no ensino formal
}

\author{
Environmental education: possible ways in formal education
}

Fábio Nilson Gomes Vilhena ${ }^{1}$

\footnotetext{
${ }^{1}$ Especialista em Educação Ambiental com Ênfase em Espaços Educadores Sustentáveis pela Universidade Federal de Ouro Preto e professor da educação básica na rede pública do município de Oiapoque-AP. E-mail: fabionilsongomesvilhena@gmail.com
}

RESUMO: O presente estudo aborda considerações sobre a Educação Ambiental no ensino formal. Demonstra uma linha do tempo sobre eventos que contribuíram para sua obrigatoriedade e discute marcos legais que estabelecem suas diretrizes curriculares. Metodologicamente, a pesquisa é de natureza exploratória/descritiva, foi realizada com professores de uma escola pública no município de Oiapoque-Amapá. Para coleta de dados utilizou-se questionário semiestruturado, com perguntas fechadas e abertas. Os resultados obtidos mostraram que a compreensão da maioria dos professores sobre Meio ambiente e Educação Ambiental está parcialmente alinhada com os princípios e objetivos das Diretrizes Curriculares Nacionais e está presente nas práticas dos professores.

Palavras chave: Educação Ambiental. Escolas Sustentáveis. Percepções. Práticas.

ABSTRACT: The present study addresses considerations about Environmental Education in formal education. Demonstrates a timeline of events that have contributed to its mandating and discusses legal milestones that set out its curriculum guidelines. Methodologically, the research is exploratory / descriptive, was carried out with teachers of a public school in the municipality of Oiapoque-Amapá. For data collection, a semi-structured questionnaire was used, with closed and open questions. The results showed that most teachers' understanding of Environment and Environmental Education is partially aligned with the principles and objectives of the National Curricular Guidelines and is present in the practices of teachers.

Key words: Environmental Education. Sustainable Schools. Perceptions. Practices.

Sumário: Introdução - 1 Panorama da Educação Ambiental no Brasil: Uma Breve Linha Do Tempo - 2 Marcos Legais que Estabelecem Diretrizes Curriculares Nacionais para Educação Ambiental - 3 Correntes Descritas por Lucie Sauvé - 4 Possíveis Caminhos para Discutir Educação Ambiental no Ensino Formal - 5 Resultados e Discussões - Considerações Finais - Referências. 


\section{INTRODUÇÃO}

O ensino da Educação Ambiental no âmbito formal tem se tornado relevante em significativas proporções. Pois foram criadas legislações que tratam da obrigatoriedade da mesma nos diversos segmentos da sociedade. Entre eles, entende-se como um forte aliado, a educação. Neste sentido se observa que foram tomadas várias medidas que subsidiassem o trabaIho dos educadores nas redes de ensino. Um exemplo é inserção do tema Meio Ambiente nos Parâmetros Curriculares Nacionais (PCN) como propostas transversais e interdisciplinares.

À luz da temática se entende como relevante investigar qual a percepção sobre Meio Ambiente e Educação Ambiental por parte dos professores atuantes na educação básica, da rede municipal de Oiapoque, no Amapá. É possível inferir que o professor poderá desempenhar papel importante na vida dos alunos e influenciar nas suas decisões acerca do seu ambiente de vivência. Desta forma é pertinente ressaltar que as concepções dos professores podem induzir e incentivar as mudanças nos hábitos dos alunos.

A escolha do tema ocorreu em razão de observar a discussão sobre a Educação Ambiental e Meio Ambiente de forma superficial durante a revisão do Projeto Político Pedagógico (PPP) da Escola Maria Leopoldina, no município de Oiapoque-AP.

Considerando que a Educação Ambiental é uma ciência social e tem como sua meta principal formar cidadãos capazes de compreender o mundo no sentido de que este indivíduo possa situar o conjunto de transformações partindo da área local para a global ou vice-versa e que estes indivíduos possam intervir conscientemente no meio em que vivem em prol de meIhorar sua qualidade de vida.

Este estudo apresenta discussões sobre a Educação Ambiental como instrumento capaz de possibilitar aos sujeitos tal feito. Desta forma é importante entender como este campo do conhecimento se estruturou no Brasil e que propostas as "diretrizes" recomendam. Neste sentido, para fundamentar esta pesquisa quanto ao panorama da Educação no Brasil, buscouse respaldo em leis, resoluções e decretos que tratam desta temática, bem como na autora Zanon (2015). Quanto à proposição de possíveis caminhos para se discutir Educação Ambiental no ensino formal, apresenta-se fundamentação em autoras como Pereira (2015); Zanon (2015) e Brasil (1997).

O problema abordado é “Qual é a percepção de Meio Ambiente e Educação Ambiental por parte dos professores atuantes no ensino fundamental I e II"? E à Metodologia empregada foi realizado um estudo de caso na Escola Municipal Maria Leopoldina (Oiapoque-AP), a mesma foi considerada ambiente propício ao desenvolvimento deste trabalho. Inicialmente realizou-se revisão bibliográfica e na sequência levantamentos de dados por meio de questionário e consequente análises dos resultados.

Para o presente artigo foram levantadas as seguintes hipóteses: Considera-se que os educadores não compreendem a importância e os conceitos de Meio Ambiente e Educação Ambiental, em razão de não terem tido um aprofundamento teórico-metodológico em suas formações; que o ensino de Educação Ambiental pautado nas diretrizes curriculares nacionais vem sendo negligenciado (Brasil 1997). 
Para tratar da Educação Ambiental no âmbito escolar, tornou-se necessário compreender um pouco de sua evolução no Brasil, neste sentido são considerados pontos na fundamentação teórica sobre a Educação Ambiental. Primeiramente, considera-se importante traçar uma breve linha do tempo sobre marcos que tratam da criação de legislações inerentes a Educação Ambiental correspondentes até meados da década de 1980. Posteriormente, abordam-se aspectos referentes a marcos legais sobre Educação Ambiental a partir da década de 1980. Na sequência aspectos referentes às quinze correntes de Educação Ambiental descritas por Sauvé (2016) com enfoque na corrente crítica. E por fim possíveis caminhos que são orientados a luz das diretrizes curriculares nacionais, como PCN de Meio Ambiente, a publicação Escolas Sustentáveis e Com-Vida: Processos formativos em Educação Ambiental.

\section{PANORAMA DA EDUCAÇÃO AMBIENTAL NO BRASIL: UMA BREVE LINHA DO TEMPO}

Para dialogar sobre este subtema recorreu-se a autora Zanon (2015), que ao produzir um vídeo de apresentação da disciplina "Panorama da educação Ambiental no Brasil e sua organização", a mesma menciona a produção de um texto, que contém uma breve linha do tempo mais moderna, pois, destaca acontecimentos inerentes à Educação Ambiental no Brasil mais recentes, que, por sua vez, foram provocados por eventos mais antigos. Também, relatam-se acontecimentos importantes para discussão de Educação Ambiental no Brasil nos dias atuais.

A autora considera que tantos os eventos mais recentes quanto os mais antigos, são importantes porque recentemente eles foram provocados pelo que se pode chamar de movimento ambientalista. Visto que este movimento a partir da década de 1960 teve forte atuação na determinação de políticas públicas e eventos importantes cujo estão citados no texto produzido por Zanon (2015).

Em se tratando de acontecimentos que foram de extrema importância para a disseminação e estruturação de políticas que dispõe sobre a legislação ambiental no Brasil, se apresentará sob o olhar de Zanon (2015) marcos que se consideram relevantes para esta pesquisa, conforme o quadro a seguir, referente a linha do tempo no período de 1605-1965 o qual descreve as leis de proteção das florestas, da exploração do trabalho livre e da utilização da água para a indústria.

\begin{tabular}{|c|l|}
\hline \multicolumn{2}{|c|}{ Quadro 1 - Linha do tempo de eventos antigos } \\
\hline ANO/LEI & \multicolumn{1}{c|}{ RESUMO } \\
\hline 1605 & $\begin{array}{l}\text { Regimento do Pau-Brasil, considerado como a primeira Lei de proteção } \\
\text { florestal no Brasil, pois se exigia autorização real para o corte do Pau-Brasil. }\end{array}$ \\
\hline 1799 & $\begin{array}{l}\text { Primeiro regimento de Cortes de Madeira - Esse Dilema estabelecia rigoro- } \\
\text { sas regras para a derrubada de árvores, além de outras restrições. }\end{array}$ \\
\hline 1802 & $\begin{array}{l}\text { Por recomendação de José Bonifácio (Intendente Geral das Minas e Metais } \\
\text { do Reino) foram baixadas as primeiras Instruções para se reflorestar a cos- } \\
\text { ta brasileira, já bastante devastada. Magalhães (2002 apud Zanon, 2015) }\end{array}$ \\
\hline 1808 & Cria-se o Jardim Botânico do Rio de Janeiro, considerado por Magalhães \\
\hline
\end{tabular}




\begin{tabular}{|c|c|}
\hline & $\begin{array}{l}\text { um marco para a proteção ambiental brasileira, por tratar-se de "nossa } \\
\text { primeira unidade de conservação, destinada a preservar espécies e estimu- } \\
\text { lar estudos científicos, além do importante aspecto educativo". (Idem p. } \\
\text { 29), ressalta-se que esta medida é de estrema importância, pois a criação } \\
\text { desta reserva tem caráter conservacionista e não mais econômico que } \\
\text { foram o foco de algumas medidas/legislações anteriores. }\end{array}$ \\
\hline Lei das terras de 1850 & $\begin{array}{l}\text { Garantia aos produtores rurais da propriedade privada, garantindo a explo- } \\
\text { ração do trabalho livre pelos senhores donos da terra; }\end{array}$ \\
\hline $\begin{array}{l}\text { Código das águas - } \\
1934\end{array}$ & Regulamenta inclusive a utilização da água para uso industrial; \\
\hline Lei $4771 / 65$ & Institui o Código Florestal \\
\hline
\end{tabular}

Fonte: Zanon ( 2015)

É evidente que existem outros instrumentos legais que tratam especificamente da legislação ambiental brasileira, porém, acredita-se que os instrumentos citados anteriormente são os principais e suficientemente esclarecedores quando se trata de marcos legais mais antigos correspondentes até meados da década de 1980. Na sequência serão apresentados instrumentos legais que tratam da Educação Ambiental a partir da década de 1980 até 2017.

\section{MARCOS LEGAIS QUE ESTABELECEM DIRETRIZES CURRICULARES NACIONAIS PARA EDU- CAÇÃO AMBIENTAL}

Há décadas que se tem certa preocupação com a forma como o ser humano tem se apropriado dos recursos naturais. A discussão sobre meio ambiente vem crescendo com relação a proteção no Brasil e no mundo na medida em que os tempos vão avançando. No passado havia a crença de que na terra, a chamado biosfera possuía tantos elementos naturais, florestas, animais, árvores, recursos minerais, solos, que o homem poderia utilizar o quanto quisesse que eles seriam ilimitados. Mas, no decorrer do tempo houve a percepção que deve haver uma limitação na utilização dos recursos naturais e se eles forem utilizados acima da capacidade de suporte dos ecossistemas, a humanidade irá transformar o planeta levando-o ao caos.

Em razão desse contexto, indivíduos (movimentos ambientalistas) colocam-se como verdadeiros protagonistas em defesa da natureza. Neste sentido, muitos foram os encontros na tentativa de apresentar medidas que resultem em possíveis soluções, como por exemplo, provocar mudanças no ser humano para conservação e preservação do meio ambiente. Autores como Grun (2012), Reigota (2014) e Cunha e Coelho (2012) elucidam períodos e razões de forma mais específicas para o que se chama de Educação Ambiental.

Grun (2012) ao buscar uma base epistemológica para discutir a educação ambiental, vincula a ética mencionando o experimento da bomba atômica, em julho de 1945 no México, liderada pelo físico Oppenheimer. E posteriormente as bombas jogadas sobre Hiroshima e Nagasaki. Ainda afirma que, ironicamente, essas bombas plantaram as primeiras sementes do ambientalismo.

Reigota (2014) cita o Clube Roma, como evento que legitima a Educação Ambiental no 
cenário Internacional. Pois na reunião ao discutir o consumo e as reservas de recursos naturais não-renováveis, conclui de forma clara a necessidade de mudanças na estrutura das nações provocando um intenso debate com muitas críticas. Sendo colocado o problema ambiental em nível planetário, tendo consequência em 1972, a Primeira conferência Mundial de Meio Ambiente. Então a partir daí surge uma resolução importante, o dever de educar o cidadão para a solução de problemas ambientais.

Cunha e Coelho (2012), identificam três tipos de políticas ambientais: as regulatórias, as estruturadoras e as indutoras. É relevante a este trabalho as indutoras, pois elas se referem a ações que objetivam influenciar o comportamento de indivíduos ou grupos sociais. Os autores mencionam que

Foi somente no século XX que a preocupação com o meio ambiente resultou, no Brasil, na elaboração e implementação de políticas públicas com caráter marcadamente ambiental, especialmente a partir da década de 70 , quando aumenta a percepção de que a degradação do planeta pode ter efeitos irreversíveis e catastróficos. (CUNHA; COELHO, 2012, p. 45).

Como resultado dessas políticas criou-se legislações que dispõe sobre a obrigatoriedade da inserção da Educação Ambiental nos diversos segmentos da sociedade. O quadro a seguir sintetiza os marcos legais que estabelecem Diretrizes Curriculares Nacionais para Educação Ambiental.

Quadro 2 - Marcos legais mais "modernos"

\begin{tabular}{|c|c|}
\hline LEIS & RESUMO \\
\hline Lei 6902/81 & $\begin{array}{l}\text { Que dispõe sobre a criação de estações ecológicas, Áreas de prote- } \\
\text { ção Ambiental, e dá outras providências; }\end{array}$ \\
\hline $\begin{array}{l}\text { A Lei no } 6.938 \text {, de } 31 \text { de } \\
\text { agosto de } 1981\end{array}$ & $\begin{array}{l}\text { Dispõe sobre a Política Nacional do Meio Ambiente; (Alterada em } \\
\text { alguns pontos pela Lei } 7008 / 89 \text { regulamentada pelo decreto } \\
99274 / 90 \text { ). O inciso X do artigo 20; estabelece que a educação ambi- } \\
\text { ental deve ser ministrada a todos os níveis de ensino, objetivando } \\
\text { capacitá-la para a participação ativa na defesa do meio ambiente; }\end{array}$ \\
\hline $\begin{array}{l}\text { Constituição da República } \\
\text { Federativa do Brasil, de } \\
\text { 1988, no inciso VI do § 10 } \\
\text { do artigo } 225\end{array}$ & $\begin{array}{l}\text { Que dispõe sobre os direitos ao meio ambiente ecologicamente e- } \\
\text { quilibrado bem de uso comum de todos e essencial a sadia qualidade } \\
\text { de vida. }\end{array}$ \\
\hline $\begin{array}{l}\text { A Lei no } 9.394 \text {, de } 20 \text { de } \\
\text { dezembro de } 1996\end{array}$ & Lei de Diretrizes e Bases da Educação Nacional (LDB); \\
\hline $\begin{array}{c}\text { A Lei no } 9.795, \text { de } 27 \text { de } \\
\text { abril de } 1999\end{array}$ & $\begin{array}{l}\text { Regulamentada pelo Decreto no } 4.281 \text {, de } 25 \text { de junho de 2002; } \\
\text { Dispõe sobre a educação ambiental, institui a Política Nacional de } \\
\text { Educação Ambiental e dá outras providências. }\end{array}$ \\
\hline $\begin{array}{c}\text { Parecer CNE/CP no 8, de } 6 \\
\text { de março de } 2012\end{array}$ & $\begin{array}{l}\text { Estabelece as Diretrizes Curriculares Nacionais para a Educação Am- } \\
\text { biental. É homologado por Despacho do Ministro de Estado da Edu- } \\
\text { cação, publicado no DOU de } 30 \text { de maio de 2012; }\end{array}$ \\
\hline
\end{tabular}

Fonte: Zanon e Garcia, 2015 
Então, a partir desse cenário surge o ensino de Educação Ambiental formal, ou seja, a escolarização dessa temática que de acordo com Brasil (2016),

Entende-se por educação ambiental na educação escolar a desenvolvida no âmbito dos currículos das instituições de ensino públicas e privadas, englobando: I - educação básica; a) educação infantil; b) ensino fundamental; c) ensino médio; II - educação superior; III - educação especial; IV - educação profissional; V - educação de jovens e adultos. (BRASIL, 2016, p. 3)

Neste sentido a figura do professor é essencial para compor o grupo dos que estão dispostos a contribuir para que se tenha um ambiente menos degradado e discutir a sustentabilidade como meio para garanti-lo para as presentes e futuras gerações. Como mencionado antes, a figura do professor é imprescindível para a disseminação da Educação Ambiental. Portanto, se torna relevante evidenciar que os mesmos necessitam trabalhar esta área do conhecimento de forma transversal e interdisciplinar para que estimule os indivíduos a adotarem uma postura de "sujeitos ecológicos". Segundo, Carvalho (2007) o Sujeito ecológico

[...] é, então, um modo de descrever um conjunto de ideais que inspira atitudes ecologicamente orientadas. O sujeito ecológico é incorporado pelos indivíduos ou pessoas que adotam uma orientação ecológica em sua vida, que pode ter efeito sobre instituições que se definam por essa orientação. O sujeito ecológico, portanto, designa a internalização ou subjetivação de um ideário ecológico. (CARVALHO, 2007, p. 136).

Diante do argumento da autora, é possível observar que para internalizar o ideário ecológico, os indivíduos necessitam de uma espécie de guia. De maneira que este guia no âmbito formal é o educador ambiental. Sobre o educador ou educadora ambiental Reigota ressalta que

[...] ser educador ou educadora ambiental é uma identidade, um reconhecimento de si muito mais que uma profissão como outra qualquer, que exige apenas conhecimentos técnicos e habilidades específicas. Uma pessoa que se considera um profissional da educação ambiental, além de seus conhecimentos técnicos e habilidades específicas, não negligencia nem coloca em segundo plano a sua militância e seu compromisso político de construção de uma sociedade justa, democrática e sustentável. (REIGOTA, 2014, p. 93)

Neste sentido é possível afirmar que sujeito ecológico e educador ambiental se assemelham quanto as suas contribuições. Pois,

[...] o sujeito ecológico, enquanto um educador ambiental, se atenta à questão da diversidade cultural e de suas implicações nas relações socioambientais, se preocupando com os indígenas, quilombolas, ribeirinhos, populações tradicionais em geral, observando suas culturas, suas necessidades, seus saberes e suas contribuições para um mundo mais sustentável. (Educação Ambiental, Sujeitos, Identidades, 2014-2016, p. 7). 
De forma que ambos têm imenso potencial quando se trata de influenciar no melhoramento da relação entre a humanidade e a natureza. (REIGOTA, 2014). Loureiro (2006 apud Wiziakc; Correia, 2013, p. 3) esclarece que educadores ambientais, de modo unitário, são sujeitos pedagógicos, focados no ensino, na aprendizagem e em mudanças de valores e atitudes; ecológicos, pois percebem dimensões essenciais presentes na relação sociedadenatureza; e políticos, pois “... a educação é uma prática social, vinculada ao fazer história, ao problematizar a realidade e transformá-la, ao produzir e reproduzir conhecimentos, valores e atitudes.", sendo "parte constituinte e constituída da sociedade e da vida pública".

Nota-se que a Educação Ambiental tomou uma grande dimensão. Por essa razão considera-se necessário observar como esta área do conhecimento está sendo desenvolvida no âmbito do ensino formal. Neste sentido um mapeamento da percepção dos professores sobre a Educação Ambiental e Meio Ambiente, facilitará possíveis discussões no sentido de sugerir caminhos viáveis para a construção de propostas engajadoras. Para tanto como suporte metodológico considera-se as correntes descritas por SAUVÉ (2004; apud ZANON, 2015) porque elas contribuem de forma significativa no auxílio do planejamento de atividades que dizem respeito ao ensino de Educação Ambiental.

\section{CORRENTES DESCRITAS POR LUCIE SAUVÉ}

As correntes servem para pesquisadores, professores, pedagogos, animadores, associações, se guiarem ao planejar atividade inerente ao ensino de temas relacionados ao meio ambiente. De acordo com Sauvé (2004 apud ZANON, 2015) as correntes podem ser classificadas em dois grandes grupos: as mais antigas e as mais recentes. Compondo o grupo das mais antigas as seguintes correntes: naturalista, conservacionista/recursista, resolutiva, sistêmica, científica, humanista, moral/ética, a elas atribui um caráter mais tradicional e de utilização mais recorrente nas décadas de 1970 e 1980.

Neste sentido consideram-se breves comentários sobre os focos de algumas. A corrente naturalista tem o grande foco para o ambiente a própria relação com a natureza; A conservacionista/recursista está voltada para o ambiente como fonte de recurso. É muito utilizada na área mais voltada para a gestão ambiental dos recursos naturais. Observa-se crise hídrica que perpassa por todo o globo, tornando-se a água um recurso limitado em áreas que vão desde atividades produtivas (indústrias), como em áreas agrícolas até chegar ao uso doméstico. Em geral, utiliza-se esse recurso, com desperdício, portanto, necessita-se repensar esse processo para que este bem precioso e fundamental se mantenha.

A resolutiva está voltada para a resolução de problemas em razão do uso intenso dos recursos e o descarte inadequado dos resíduos sólidos, sendo este visto como um problema. A Sistêmica se coloca como uma forma interligada, pois para proteger a água, deve-se proteger as vegetações. No grupo das mais recentes: correntes holísticas, biorregionalista, práxica, crítica, feminista, etnográfica, da ecoeducação e da sustentabilidade.

A corrente holística busca uma visão além de um conjunto de sistemas interligados como já citado. Possui uma visão global; A biorregionalista está relacionada com a visão de 
pertencimento. Tenta fazer com que as pessoas reconheçam as características ambientais do espaço onde vivem, para que saibam onde elas estão.

Apesar de não ser foco deste trabalho, aprofundar cada corrente na íntegra, considera-se elucidar primordialmente as correntes da ecoeducação, pois a mesma foca na utilização da educação como ferramenta para propagar a temática Meio Ambiente, que por sua vez é proposta deste trabalho; a corrente da sustentabilidade visa o uso racional dos recursos com objetivo de preservar para as futuras gerações

E finalmente a corrente crítica que vislumbra discutir de forma profunda "as dinâmicas sociais que se encontram na base das realidades e problemáticas ambientais, análise de intenções, de posições, de argumentos, de valores explícitos e implícitos, de decisões e de ações dos diferentes protagonistas de uma situação". (SAUVÉ, 2004). Consideram-se os argumentos referentes às correntes, para quando se pensar em trabalhar a Educação Ambiental se faça uso das mesmas como auxiliadora no processo de ensino-aprendizagem entre os envolvidos.

\section{POSSÍVEIS CAMINHOS PARA DISCUTIR EDUCAÇÃO AMBIENTAL NO ENSINO FORMAL}

Antes de apresentar a compreensão de conceitos da Educação Ambiental no ensino formal considera-se relevante refletir sobre o papel da "educação", que, por sua vez, na visão de CHALITA, (2002 apud CUBA, 2010)

[...] constitui-se na mais poderosa de todas as ferramentas de intervenção no mundo para a construção de novos conceitos e consequente mudança de hábitos. É também o instrumento de construção do conhecimento e a forma com que todo o desenvolvimento intelectual conquistado é passado de uma geração a outra, permitindo, assim, a máxima comprovada de cada geração que avança um passo em relação à anterior no campo do conhecimento científico e geral (p. 27).

Sob esta visão convém pensar a educação ambiental no ensino formal. Isto é, remete refletir o que se discute além da sua previsão nas legislações, ou seja, é necessário compreender e se apropriar das teorias e conceitos propostos por indivíduos que estão engajados neste processo. Neste sentido, Viegas discute Educação Ambiental no ensino formal como sendo

[...] o processo, mediado pela realidade que envolve estudantes, professores, funcionários (comunidade escolar), familiares e comunidade no entorno da escola, no desenvolvimento na temática ambiental, objetivando propiciar aos envolvidos uma compreensão das questões vinculadas a este tema, permitindo assim o desenvolvimento de valores e atitudes conscientes em prol das questões ambientais. (VIEGAS, 2014, p. 3)

Neste cenário emerge as escolas sustentáveis como alternativas possíveis para "discutir" a Educação Ambiental no ensino formal articulando Gestão, Currículo e Espaço. Dessa 
forma compreende-se como escola sustentável

[...] um local onde se desenvolvem processos educativos permanentes e continuados, capazes de sensibilizar o indivíduo e a coletividade para a construção de conhecimentos, valores, habilidades, atitudes e competências voltadas para a construção de uma sociedade de direitos, ambientalmente justa e sustentável. (BRASIL, 2012, p. 10)

Ressalta-se que uma escola sustentável "é aquela que transforma seus hábitos e sua lógica de funcionamento, reduz seu impacto ambiental e se torna referência de vida sustentável para sua comunidade, ampliando seu escopo de ação para além das salas de aulas" (BRASIL, 2011, p. 6). Com base no supracitado, possíveis caminhos podem ser trilhados na tentativa de se inserir discussões sobre a Educação Ambiental nas redes públicas de ensino. Conjuntamente a esta estratégia serão discutidas outras possibilidades. Para tanto se recorreu aos PCN de Meio Ambiente e na publicação Escolas Sustentáveis e Com-Vida: processos formativos em educação ambiental, como instrumentos balizadores.

Brasil (1997) traz uma importante contribuição de como os educadores podem discutir o Meio Ambiente em sua prática pedagógica. No entanto, se fará referência apenas a pontos considerados relevantes para esta pesquisa. $O$ documento inicialmente contextualiza o cenário que se enfrenta atualmente, ou seja, a crise ambiental que se apresenta como um desafio para aqueles que amam a natureza, que por sua vez está pedindo socorro.

Ainda discute conceitos como proteção, conservação, preservação, recuperação e reabilitação. Pois considera que as escolas devem compreender seus significados porque eles são utilizados com frequência nas legislações como formas cuidadosas de se lidar com o meio ambiente (BRASIL, 1997).

Outro fator relevante a ser evidenciado é a forma de organização dos conteúdos, pois eles são compostos por três blocos, que são: os ciclos da natureza, sociedade e meio ambiente e manejo e conservação ambiental, assim.

Os conteúdos de Meio Ambiente serão integrados ao currículo através da transversalidade, pois serão tratados nas diversas áreas do conhecimento, de modo a impregnar toda a prática educativa e, ao mesmo tempo, criar uma visão global e abrangente da questão ambiental. As áreas de Ciências Naturais, História e Geografia serão as principais parceiras para o desenvolvimento dos conteúdos aqui relacionados, pela própria natureza dos seus objetos de estudo.(BRASIL, 1997, p. 37).

Os PCN ainda abordam a Educação Ambiental a partir de três noções centrais: Meio Ambiente, Sustentabilidade e Diversidade. Indicam que o conteúdo a ser trabalhado deve apontar para os seguintes aspectos: conceitos, atitudes e procedimentos (BRASIL, 1997).

Alinhado ao PCN, a publicação Escolas Sustentáveis e COM-VIDA: processos formativos em educação ambiental fazem referência à proposta metodológica para o ensino do tema meio ambiente. Ela traz conceitos importantes sobre espaços educadores sustentáveis, que por sua vez "são aqueles que têm a intencionalidade de educar para a sustentabilidade; eles 
mantêm uma relação equilibrada com o meio ambiente e compensam seus impactos com desenvolvimento de tecnologias apropriadas" (ZANON, 2015, p. 12).

Considerando o pensamento "todo espaço construído é resultado da história das pessoas, dos grupos que nele vivem, trabalham, produzem." (ZANON, 2015, p. 25), enfatiza que precisa "transformar a escola em espaço vivo, integrando a natureza, de forma a criar um ambiente bonito, aconchegante e motivador, que estimule a inovação, a aprendizagem e reflita o cuidado com o ambiente e com as pessoas". (ZANON, 2015, p. 25). Pois, "Quem vive a escola pode manifestar fortes vínculos com esse lugar, identificando-se ou rejeitando os laços de pertencimento, reconhecendo ou estranhando a necessidade da escola em sua vida"(ZANON, 2015, p. 26).

Neste sentido como estratégia que vise estimular indivíduos que reconheçam a necessidade da escola em sua vida, aderir o COM-VIDA torna-se de extrema relevância, pois, "tem como um de seus objetivos a criação de espaços na escola que possibilitem o pleno exercício da cidadania. Espaços de debates para a tomada de decisões compartilhadas entre gestores (as), professores (as), e estudantes"(ZANON, 2015, p. 49). Diante das colocações observa-se que existem propostas mensuráreis e podem ser aplicadas com o objetivo de promover a Educação Ambiental de forma que esta seja beneficente a comunidade.

\section{RESULTADOS E DISCUSSÕES}

Neste tópico serão apresentados os resultados levantados a partir dos questionários aplicados aos professores. Inicialmente são apresentadas as características, como formação acadêmica, tempo de serviço no magistério e na sequência serão apresentadas as respostas obtidas com os questionários referente as percepções dos professores sobre Educação Ambiental e Meio Ambiente. Com relação ao tempo de serviço, a grande maioria tem mais de dez anos de profissão. $O$ que lhes garante grande experiência pedagógica, que enriquece sua contribuição no processo ensino-aprendizagem dos educandos.

No que se refere à situação profissional dos 18 professores, há um maior número de educadores concursados (16), o que poderá garantir melhor planejamento sobre a inserção da educação ambiental em longo prazo, pois, não há o risco de interromper alguma atividade por problemas com transferência desses profissionais.

Em relação a formação continuada, dois momentos foram considerados. O primeiro é referente ao curso de graduação (curso e ano de conclusão). O segundo, referente ao curso de especialização, (curso, ano de conclusão). A seguir será tratado especificamente sobre número de professores que possuem graduação e seus respectivos cursos. E na sequência sobre os professores que possuem formação em especialização (curso que se formou).

Sobre o curso de graduação, dos 18 participantes, 17 são habilitados com curso superior completo, e apenas um está em andamento. Ainda se tratando de formação continuada foi possível verificar o número de graduados (17) e especialistas (9).

Com relação ao curso de especialização poucas são as formações que tem relação mais direta com o campo ambiental. Pois, os 18 professores participantes estão distribuídos da 
seguinte forma: especialista em Língua Portuguesa (um), Educação Especial (um), Metodologia do Ensino na Educação Superior (um), Gestão e Docência (um), tecnologia Educacional (um), Fisiologista (um), Orientador Educacional (um), Gestão e Docência do Ensino Superior(um). No entanto tais são de muita relevância, pois, mesmo não tendo forte relação com o campo ambiental, nota-se que os profissionais são bem qualificados e podem abranger a causa ambiental.

No que diz respeito à presença do tema Meio Ambiente e Educação Ambiental nas formações acadêmicas, verificou-se que dos 18 professores, 13 responderam que sim, sendo que os demais responderam não. Desta forma foi possível verificar claramente que a temática meio ambiente e Educação Ambiental se apresentaram com maior presença nas formações dos professores entrevistados.

Torna-se possível ainda perceber a fluência que se discutiu tais temáticas. Pois dos 13 que informaram sim, cinco tiveram a disciplina ministrada de forma aprofundada, o que se pode considerar um quantitativo relevante no sentido de inserir o tema meio ambiente de forma estruturada na educação básica. Por outro lado, dos 13 que responderam sim, oito tiveram a disciplina trabalhada apenas de forma básica, ou seja, de forma sucinta, sem muito impacto.

Diante das descrições apresentadas, é relevante considerar que a temática meio ambiente, está sendo discutida, seja no nível básico ou no ensino superior. Portanto, remete observar como este ensino tem impactado na prática dos professores que sofreram essas influências em suas formações. Diante do exposto foram tratadas questões referentes aos conceitos, temas e metodologias descritos pelos professores participantes.

A questão um, buscou verificar se a escola possui alguma ação ou projeto sobre o meio ambiente. Observou-se que dos 18 participantes nove informaram que não, seis responderam sim e três não responderam.

A questão dois, tentou identificar que temática o projeto discute. Visto que houve respostas diversas. Sendo citado os seguintes projeto e seus respectivos temas: 1) Meio ambiente: temas - reciclagem, higiene, sustentabilidade e conscientização; 2) Reciclagem/Dengue: temas - reciclagem, doenças causadas pelo lixo; 3) Reciclar: temas - busca pela conscientização ambiental.

A questão três buscou compreender se os professores trabalham o tema Meio Ambiente em suas aulas e com que frequência. Observou-se que dos 18 professores, 15 trabalham e três não.

A questão quatro tentou demonstrar a assiduidade que os professores trabalham a Educação Ambiental. Visto que (um) trabalha diariamente, (seis) semanalmente, (um) mensalmente e (três) apresentaram respostas individuais (ocasionalmente, quando há necessidade e quinzenalmente, respectivamente).

A questão cinco buscou identificar as razões pelas quais os professores participantes consideram trabalhar o meio ambiente. As razões descritas foram as mais diversas, no entanto foi possível agrupá-las em três categorias.

1) Preservação ambiental (seis professores), exemplificada na seguinte resposta: 
[...] "é para que eles [alunos] possam aprender a respeitar o meio onde vivem e ajudar a divulgar a importância da preservação ambiental" (E4 - 40 ano).

2) Conservação do meio ambiente (dois professores)

[...] "é para que eles [alunos] possam conservar e sensibilizar com os outros sobre o que é meio ambiente" (E11 - 50 ano).

3) Conscientização (cinco professores)

[...] "para tentar aproximá-los [alunos] de uma conscientização sobre o meio ambiente. Pois cuidar do nosso planeta é responsabilidade de todos" (E5 - 3ㅇano).

A questão seis visou detectar o conceito de meio ambiente por parte dos professores. As respostas se apresentam sob duas categorias: (1) Meio em que vivemos (quatro professores), "[...] é o meio em que vivemos" (E18 - Geografia) e (2) Visão naturalista (cinco professores), "É tudo que existe na natureza como o ar, a água, o solo, as plantas, os animais" (E5 - 3으 ano).

As respostas anteriores se aproximam do que Sauvé $(2004$, p. 19) considera como corrente naturalista, pois, "está centrada na relação com a natureza e seu enfoque educativo pode ser cognitivo (aprender com coisas sobre a natureza), experiencial (viver na natureza e aprender com ela), afetivo, espiritual ou artístico (associando a criatividade humana à da natureza)".

A questão sete buscou elucidar os temas trabalhados pelos professores entrevistados. Os temas são: Preservação do meio ambiente (quatro); plantas (dois); desenvolvimento sustentável (dois); reciclagem (oito); lixo - descarte, reciclagem (dois); poluição (um); ecossistemas (um); biomas - fatores bióticos e abióticos (um); água - poluição e preservação (um); ética (um); caráter social (um); doenças (um); queimadas (um); saneamento (um); higiene - ambiente escolar (um); paisagens - rural e urbana (um); ar (um); casa (um).

Diversos são os temas e conteúdos trabalhados pelos educadores. Cabe uma ponderação, mesmo "não havendo conteúdo específico e sim vários, isto é, dependendo das faixas etárias a que se destina e dos contextos educativos em que se processam as atividades" (REIGOTA, 2014, p. 61), os PCN de Meio Ambiente oferecem sugestões bastante significativas que podem auxiliar os educadores quanto às escolhas.

Entre os temas descritos pelos professores, a reciclagem aparece como o mais citado (oito vezes). Convém refletir o posicionamento crítico sobre o significado político-ideológico da reciclagem, termo utilizado por Layargues et. al.(2002). Conforme Layargues et. al. (2002 apud Carvalho 2007)

[...] Existem duas matrizes discursivas sobre a questão ambiental: um discurso ecológico oficial, enunciado pelo ambientalismo governamental, representante da ideologia hegemônica e encarregado de manter os valores culturais instituídos na sociedade; e um discurso ecológico alternativo, proferido pelo ambientalismo original strictu sensu, corporificado pelo movimento social organizado, representante da ideologia contra hegemônica e encarregado de disseminar valores subversivos à ordem social e econômica instituída. (CARVALHO, 2007 apud LAYARGUES, et. al. 1991, p. 181). 
Interessa a esta pesquisa comungar com a segunda ideia, pois visa desmitificar a lógica do consumismo esclarecendo o discurso governamental sobre a reciclagem. No entanto, vale ressaltar a importância da reciclagem para o meio ambiente em diversos contextos.

A questão oito descreveu as metodologias utilizadas no trabalho com educação, pelos professores participantes. As metodologias citadas se evidenciaram com aplicação em sala de aula. Foram elas: utilização de livros (dois); aula dialogada (dois); utilização de vídeos (dez); utilização de cartazes (cinco); conversas informais (três); atividades xerocadas (um); oficinas de reciclagem (três); pesquisas (quatro); seminário (dois); utilização de texto (dois); uso de slide (três); debates (um); dinâmicas (um); uso de desenhos (dois).

A questão nove verificou se os alunos se interessam pela temática ambiental, quando trabalhada em sala de aula. Nos depoimentos levantados, os 18 professores informaram que os alunos se interessam, pois, sentem forte afinidade por esta temática, veja o depoimento "A temática ambiental desperta o interesse deles e a curiosidade dos alunos, pois eles percebem que por meio dela podemos melhorar nosso planeta". (E12 - 5o ano) Carvalho (2007) menciona que há um engajamento político por parte dos jovens em razão de haver problemas concretos.

A questão dez identificou o entendimento dos professores sobre Educação Ambiental. As respostas foram agrupadas em duas categorias descritas a seguir.

1) Processo que discute a problemática ambiental (11 professores). Observe a resposta, "Processo ou mecanismo utilizado no intuito de assegurar a preservação e conservação do meio ambiente, com vistas a buscar alternativas de desenvolvimento sem causar tantos impactos". (E 16 - Geografia), a resposta corresponde ao argumento descrito pelos PCN, quando se observa que a "perspectiva ambiental oferece instrumentos para que o aluno possa compreender problemas que afetam a sua vida, a de sua comunidade, a de seu país e a do planeta" (Brasil, 1997, p. 35).

2) Ideia de fazer parte do meio ambiente (um professor) "É a consciência que o ser humano é parte da natureza e do meio ambiente em que ele está inserido" (E-15), o argumento citado está paralelo a corrente naturalista entendida por Sauvé (2004), pois apresenta a relação com a natureza.

Diante das respostas descritas é possível fazer uma breve análise evidenciando que o tema ambiental é trabalhado por todos os professores sob diversos temas e metodologias. Entretanto, ainda correspondem parcialmente às propostas elucidadas neste trabalho que por sua vez está alinhada as diretrizes curriculares nacionais. Portanto, acredita-se que para chegar à Educação Ambiental almejada e propostas pelas diretrizes curriculares, ainda se faz necessário dedicar maior empenho no sentido de se adotar o “ideário ecológico" proposto por Carvalho (2007); e necessita, ainda, de concepções claras e seguras.

Considerando que fazer apenas um diagnóstico da realidade não é suficiente, mas é de suma importância criar meios pelos quais se pratique a Educação Ambiental de fato, ou seja, intervir com ações concretas e mensuráveis. Discutiu-se materialização do COM-VIDA na escola. Utiliza-se o termo "materialização" em razão de ter se iniciado um diálogo com direção da escola pesquisada no ano de 2013. No entanto num primeiro momento não foi possível 
compartilhar a proposta com a comunidade escolar por motivos diversos.

Entretanto, já houve avanços, pois, no mês de março do ano 2016 houve uma nova tentativa. Sendo possível neste segundo momento apresentar e inserir no plano de ação da escola, a proposta de implantação do COM-VIDA. Num terceiro momento apresentou-se o projeto piloto à coordenação pedagógica. Na sequência aos funcionários da escola como docentes e profissionais de apoio. De forma que este projeto se iniciaria no segundo semestre de 2016. Porém, como afirma Brasil (1997).

É necessário ainda ressaltar que, embora recomendada por todas as conferências internacionais, exigida pela Constituição e declarada como prioritária por todas as instâncias de poder, a Educação Ambiental está longe de ser uma atividade tranquilamente aceita e desenvolvida, porque ela implica mudanças profundas e nada inócuas. (BRASIL, 1997, p. 23).

Neste sentido por falta de engajamento da comunidade, e principalmente, por parte dos articuladores, não foi possível realizar sua implantação com êxito. Mas é necessário considerar que inserir o embasamento do COM-VIDA na escola, como um instrumento que traz benefícios para a comunidade, foi um passo importantíssimo, pois acredita-se que a partir desse diálogo há uma expectativa muito forte para a materialização do COM-VIDA na escola.

Por tanto, esta pesquisa possibilitará um meio para sensibilizar os envolvidos no processo educacional, no sentido de que estes possam refletir sobre o seu papel sob a consideração de Brasil (2011), quando afirma que

A escola pode também se transformar em um espaço educador. Cabe aqui uma ponderação: dizer que pode se transformar indica que ser educador não se trata de algo inerente, implícito ao objetivo de educar. Para realizar efetivamente seu imenso potencial educador, é necessário assumir responsabilidades, dialogar sobre seus valores, comprometendo-se de forma coerente e íntegra com seus objetivos. (BRASIL, 2011, p. 13)

Alinhado a esta citação e com a discussão teórica, como possíveis caminhos para se trabalhar Educação Ambiental nas redes públicas de ensino enxerga-se a aplicação das tecnologias ambientais. Sobre este aspecto Pereira (2015) sugere, o que ela considera como um cardápio de ecotécnicas que devem ser aplicadas nas unidades educacionais, tais como: 1) Biodigestor; 2) Tinta de solo; 3) Banheiro seco; 4) Coleta seletiva; 5) Coleta de água da chuva; 6) Acessibilidade, 7) Compostagem; 8) Telhado verde; 9) Horta circular; 10) Captação de energia solar. Diante da lista considera-se para local da pesquisa as possibilidades 4, 5, 10.

\section{CONSIDERAÇÕES FINAIS}

Esta pesquisa se tornou um momento de muitos desafios e aprendizado, resultado de uma longa jornada de trabalho, pois, abordou sobre a importância da Educação Ambiental como ferramenta auxiliadora no processo de ensino aprendizagem no âmbito formal. 
Diante dos dados apresentados é possível evidenciar que os objetivos foram alcançados satisfatoriamente, visto que: 1) no questionário aplicado aos professores nota-se que Educação Ambiental se faz presente em suas práticas; 2) diversas razões são consideradas importantes pelos professores para trabalhar atemática meio ambiente, no entanto com base nas respostas, acredita-se que há uma ausência de princípios e objetivos pautados nas diretrizes curriculares nacionais que permita explorar a educação ambiental com maior eficácia; 3) foi possível evidenciar claramente os temas e as metodologias utilizadas pelos professores entrevistados.

Quanto às hipóteses levantadas considera-se que: a primeira apresenta-se refutada, pois os dados demonstram que os professores tiveram ocorrência de disciplina que tratasse do tema Meio Ambiente e Educação Ambiental em suas formações. No entanto, quanto à compreensão sobre os conceitos de Meio Ambiente e Educação Ambiental se evidencia mediante as respostas que um maior número se distanciou dos apresentados na construção teórica que por sua vez estão pautadas nas diretrizes curriculares; enquanto que a segunda se apresentou parcialmente verdadeira, pois, os dados coletados demonstraram a ocorrência da prática de Educação Ambiental, porém, correspondem parcialmente paralelas as propostas das Diretrizes Curriculares Nacionais para Educação Ambiental.

Esta análise apresenta dados de apenas um recorte num determinado momento e ambiente. Ainda assim, não tem a pretensão de esgotar possibilidades de um maior aprofundamento, podendo qualquer indivíduo aperfeiçoar este estudo. Neste sentido sugere-se como possível linha de aprofundamento uma maior discussão dos dados coletados.

Por fim este trabalho torna-se relevante por se apresentar como estratégia útil e significativa para o ensino da temática Meio Ambiente no ensino formal, oferecendo aos educadores a possibilidade de refletir suas práticas pedagógicas e assim melhorá-las. E ainda, contribui para a área de ensino das universidades, alertando sobre lacunas quanto à qualidade do ensino relacionado à temática meio ambiente oferecida pelas universidades nos cursos superiores.

\section{REFERÊNCIAS}

BRASIL. Diário oficial da União. Resolução no 2, de junho de 2002. Conselho Nacional de Educação, 2002. Disponivel em: <http://www.moodle2antigo.ufop.br/file.php/2321/Arquivos _do_Curso/Panaroma_da_Educacao_Ambiental_no_Brasil/leidediretrizes.pdf $>$. Acesso em: 8 outubro 2016.

2011.

M. D. E. Espaços educadores sustentáveis. Salto para o Futuro. Ano XXI: Boletin 7,

M. D. E. Vamos cuidar do Brasil com escolas sustentáveis: educando-nos para pensar e agir em tempos de mudanças socioambientais globais. Brasília: Secreatria, 2012.

R. F. D. Lei no 9.795, de 27 de abril de 1999. Diário Oficial, Agosto 2016. Disponivel em: <http://www.paulofreire.org/wp-content/uploads/2012/PME/politica_nac_ed_ambien tal.pdf $>$. Acesso em: 06 agosto 2016. 
S. D. E. F. Parâmetro Curriculares Nacionais: meio ambiente / saúde. Brasíla: [s.n.], 1997.

CARVALHO, I. C. M. O sujeito ecológico: a formação de novas identidades. In: MELLO, S. S. D.; TRAJBER, R. Vamos cuidar do Brasil: conceitos e práticas em educação ambiental na escola. Brasília: UNESCO, 2007. Cap. 2, p. 136-141.

CUBA, M. A. Educação Ambiental nas escolas. ECCOM, julho 2010. 23 - 31.

CUNHA, L. H.; COELHO, M. C. N. Política e Gestão Ambiental. In: CUNHA, S. B.; GUERRA, J. T. A questão ambiental: difrentes abordagens. 8a. ed. Rio de Janeiro: Bertrand Brasil, 2012. Cap. 2.

GRUN, M. Ética e Educação Ambiental: A conexão necessária. 14ạ. ed. Campinas: Papirus, 2012. - (Coleção Magistério e Trabalho Pedagógico).

LAYARGUES, P. P. O cinismo da reciclagem: o significado ideológico da lata de alumínio e suas implicações para Educação Ambiental. In: CASTRO, R. Educação Ambiental: repensando o espaço da cidadania. São Paulo: Cortez, 2002. p. 179-220.

PEREIRA, D. M. Processo formativo em educação ambiental: escolas sustentáveis e com vida: tecnologias ambientais. 2a . ed. Ouro Preto: Editora da UFOP, 2015.

REIGOTA, M. $O$ que é Educação Ambietal. 2a. ed. São Paulo: Brasiliense, 2014. - ( Coleção Primeiros Passos; 292).

SAUVÉ, L. Una Cartografía de Corrientes en Educación Ambiental. In: CARVALHO, I. C.; SATO, M. A pesquisa em Educação Ambiental: cartogrfias de uma identidade em formação. Porto Alrgre: Artmed, 2004.

L. Uma diversidade de correntes em educação ambiental. CEAD UFOP, 2016. Disponivel em: <http://www.moodle2antigo.ufop.br/file.php/2321/Arquivos_do_Curso/Pana roma_da_Educacao_Ambiental_no_Brasil/Tabelas_correntes_Educacao_Ambiental_Pesquisa _e_desafios.jpg >. Acesso em: 02 Novembro 2016.

VIEGAS, P. D. L. Prática de Educação Ambiental no âmbito do ensino formal: estudos publicados em revistas acadêmicas brasileiras (2007 a 2012). Sorocaba: [s.n.], 2014,

ZANON, Â. M. et. al. Escolas sustentáveis e Com - Vida: processos formativos em Educação Ambiental. 2a. ed. Ouro Preto: UFOP, 2015.

ZANON, Â. M.; GARCIA, Á. D. S. Educação Ambiental e mudanças de Paradigma, Ouro Preto, 2015. Disponivel em: <http://www.moodle2antigo.ufop.br/file.php/2321/Arquivos_do_Cur so/Panaroma_da_Educacao_Ambiental_no_Brasil/Artigo_-_PANORAMA_DA_EDUCACAO_A MBIENTAL_NO_BRASIL.pdf>. Acesso em: 21 Novembro 2016.

Artigo recebido em 01 de março de 2018.

Aprovado em 24 de abril de 2018. 